\title{
North-South-South collaboration as a context for collaborative learning and thinking with alternative knowledges
}

\author{
Anna-Leena Riitaoja, ${ }^{*}$ Hanna Posti-Ahokas and Hille Janhonen-Abruquah - \\ University of Helsinki, Finland
}

\begin{abstract}
This article discusses North-South-South higher education collaboration as a context for development education. We analyse an intensive course on qualitative research methods and culturally responsive education organized by a network of five universities from global South and global North. The course aimed to enhance qualitative understanding of quality learning and educational practices through approaches of contextual and cultural relevance, in line with Sustainable Development Goal 4 (SDG4). The course initiated a research-focused learning dialogue among students and researchers and encouraged participants to reflect and critique their views and to engage with alternative knowledges. Analysis of participants' course feedback highlights the opportunities and limits of NorthSouth-South collaboration for enhancing contextual, cultural and epistemological awareness for a better understanding of quality education.
\end{abstract}

Keywords: higher education, SDG4, North-South-South collaboration, qualitative methodology, culturally responsive education, alternative knowledges

\section{Introduction}

The focus of this investigation is North-South-South higher education collaboration as a context for development education. We analyse the opportunities and limits of NorthSouth-South higher education collaboration for creating a space for collaborative learning and knowledge building in ways that rely not only on Western perspectives but include also Southern knowledges in dialogue and reflection and thus foster epistemological awareness about alternative knowledges (De Sousa Santos, 2016). Our analysis builds upon Bourn's (2014a: 20) conceptualization of development education as an approach that promotes learning towards 'a global outlook, understanding of power and inequality in the world, belief in social justice and a commitment to reflection, dialogue and transformation'. Development education with a critical and reflective pedagogical approach has ushered in a significant contribution to the global Sustainable Development Goal 4 (SDG4) and to the related discussions on quality education for all. Critical development education perspectives are important for exploring learning processes and for understanding what constitutes quality education in different educational contexts, and what are the wider social and economic benefits for learners (Skinner et al., 2013). We have utilized the culturally responsive education approach (Gay, 2010) as a framework to co-analyse diverse educational contexts and practices from a quality perspective, with a special focus on equity and cultural sustainability. 
In SDG4, quality education is connected to the relevance and effectiveness of the learning, skills, and outcomes of a curriculum. These include educational outcomes, skills related to employment success and entrepreneurship, equity in education and equality in learning. According to SDG4.7, quality education also means:

that all learners acquire the knowledge and skills needed to promote sustainable development, including, among others, through education for sustainable development and sustainable lifestyles, human rights, gender equality, promotion of a culture of peace and non-violence, global citizenship and appreciation of cultural diversity and of culture's contribution to sustainable development. (https://sustainabledevelopment.un.org/sdgs)

Despite the elaborate quantitative monitoring and accountability measures in SDG4, many of its goals suggest that educational quality should not be measured exclusively by external and quantitative terms, but that instead, qualitative contextual understanding and responses to these issues are necessary (Sayed and Ahmed, 2015; Skinner et al., 2013). Further, a broader conceptualization of learning beyond measurable literacy and numeracy outcomes is necessary for recognizing the broader aims of education, such as citizenship (Sayed and Ahmed, 2015).

SDG4 also poses a challenge for higher education, by asking universities to generate and protect new knowledge and to share it for the benefit of humanity (Baijnath and James, 2015). However, Western perspectives also frame the aims and content of higher education (Stein et al., 2019a; Barrett et al., 2014; Richards, 2015). A similar critique also applies to Education for All and SDG4 goals (Jain, 2013; Stein et al., 2019a). Despite the goals of many development education programmes and instances of North-South collaboration, Western modes of thinking and doing often remain hegemonic in these efforts (Barrett et al., 2014). The recognized shift in development cooperation from North-South linkages towards South-South collaboration encourages building partnerships across the global South (see Holmarsdottir et al., 2013 for further discussion). Recognizing Western dominance in this field, development education in higher education contexts should incorporate diverse forms of knowledge and expose learners to diverse experiences and approaches, thus challenging epistemic hegemony (Barrett et al., 2014; Odora Hoppers, 2015; Richards, 2015).

When discussing higher education's contributions to global sustainable development goals, questions about the purpose and the quality of that education are critically important, especially in an increasingly unpredictable world facing growing inequality in the distribution of wealth, persistent racism, social exclusion and environmental destruction (Odora Hoppers, 2015). These are also burning questions for internationalized higher education. Internationalization has become a global endeavour in higher education but the reasoning of internationalization still relies on Western superiority of research and education, leaving little room for Southern epistemologies (Andreotti, 2010; Bhambra, 2014; Andreotti et al., 2015; De Sousa Santos, 2016; Stein et al., 2019b) or for recognizing how local experiences of education are related to global notions of education (Lehtomäki et al., 2019). For example, the discourse on twenty-first-century skills and competencies increasingly predetermines how educators understand the relevance and purpose of education, no matter that such discourse stems from the ideology of the global market economy, which has no interest in global justice or contextually relevant education (Biesta, 2009; Andreotti, 2010). Biesta (2009) points out that education should link learning and the learner to societal structures and socialize learners but also permit independence and individuality from prevailing structures and ideologies. 
The question therefore arises as to what extent should education in general, but higher education in particular, support prevailing structures, paradigms and the status quo, and to what extent should it lead to the transformation of societal structure, paradigms and the status quo? Can the quality and relevance of the higher education curriculum, teaching and learning centre only on existing understanding (Biesta, 2009)? Answering yes defines the mission of higher education as replicating current knowledge and perspectives, which forecloses the opportunity for paradigmatic transformation. This is problematic because discovering new, unexpected, or alternative insights has always been the very aim of universities and academic discussions, and the precondition of regeneration of science (Biesta, 2009; Blommaert, 2016). This is also problematic because working from the prevailing, typically Western and hegemonic, understanding and paradigms ensures that higher education protects the prevailing societal structure that maintains local and global injustice (e.g. Andreotti, 2010; Odora Hoppers, 2015). The question that follows is, to what extent are higher education and research open for paradigmatic and societal transformation, and when and how do they retreat into protecting their own status and interests?

In this article, we approach North-South-South collaboration as a potential context for developing awareness about our own convictions and perspectives. To do this, we conceive of knowledge as an actor that makes things rather than as a series of objects or facts (Foucault, 1980; Andreotti et al., 2010). This approach is directly related to problematizing the historical, political and social conditions of knowledge production and the intellectual and societal consequences that follow when we rely on official knowledge. By official knowledge we mean universal North-centric knowledge that is commonly taught in universities and public schools, as opposed to contextual indigenous and informal knowledges (e.g. Jain, 2013; Shokane and Masoga, 2018). Therefore, it is important to ask what knowledge is used and how knowledge can enable or prevent us from recognizing, examining and challenging power relations. Engaging in dialogue between cultures and contexts can make us aware of the limits of our own knowing (Andreotti, 2010). As Andreotti (2010: 236) puts it, 'our stories of reality, our knowledges, are always situated (they are culturally bound), partial (what one sees may not be what another sees), contingent (context-dependent) and provisional (they change).' Intercultural and inter-contextual dialogue can also make us more aware of the incompleteness of any knowledge (De Sousa Santos, 2016) and urge us to develop new forms of cultural understandings and ways of communication that can be useful for fighting against capitalism, colonialism and sexism, and for social justice, human dignity or human decency in different cultural contexts (De Sousa Santos, 2016: 22). Unlearning the ongoing investments in epistemic universality, according to Stein et al. (2019b), could imply a decolonial approach to global ethics in the internationalization of higher education.

When discussing SDG4, the role of educational sciences in general and teacher education in particular are important contexts for development education in higher education. Odora Hoppers (2015) describes education sciences as both an intellectual and a political endeavour, where the link between theory and practice varies on a case-by-case basis and where the policy-driven nature of the discipline itself limits the framework for knowledge generation. In their critical analysis of the quality discourse in the global education agenda, Sayed and Ahmed (2015) emphasize the importance of developing dynamic, process-orientated models of teaching and learning, together with substantive engagement with diversity and context. This provides a challenge for higher education institutions conducting educational research and educating future teachers. How does knowledge from the South make its way into the sturdy global 
North university curricula? What kind of challenge does this pose for SDG4 itself? How can we create learning spaces that are responsive to cultural diversity (Gay, 2010) and that allow other forms of knowledge to emerge (Odora Hoppers, 2015; De Sousa Santos, 2016)? Bourn (2014a) identifies social justice and critical, reflective dialogue as central to development education, also recognizing the diversity of perspectives and locations in both the global South and the global North. In our example of a North-South-South network of five universities from Tanzania, South Africa, Ghana and Finland, we discuss how a shared interest in qualitative education research and culturally responsive education was used as a context for sharing and creating a deeper understanding of quality education among scholars and students from various backgrounds.

In our network, the culturally responsive education approach was used to examine contextually relevant teaching in diverse contexts. Culturally responsive education (CRE) draws on Geneva Gay's $(2010,2013)$ theoretical thinking on culturally responsive teaching (CRT), an approach developed in the United States over 15 years. The aim of CRT is to make teaching and learning culturally and contextually meaningful, so that they make sense to the learner. Gay argues that using the cultural experiences and perspectives of ethnically diverse students can create a more meaningful learning environment and enhance engagement with social justice issues. Learning should aim for change and freedom, making it both transformative and emancipatory. To work successfully with students from different backgrounds, teachers should be able to identify internalized biases and accommodate the rich variety of students' cultural experiences into their teaching (Gay, 2010, 2013).

Gay's theoretical thinking derives from racial and ethnic inequalities and the related educational and social injustices in the United States. It focuses on power inequalities and discrepancies between contexts, that is, between culture at school and at home (Gay, 2013). However, some scholars suggest that, alongside cultural issues, there should be a more explicit emphasis on political and historical dimensions and that this could provide more tools for discussing issues of racism and social injustice (Beauboeuf-Lafontant, 1999). Moreover, there is an argument that CRT does not pay enough attention to wider power structures and hierarchies that create such discrepancies between school and home. In doing so, CRT may turn its gaze from issues of power dynamics to a neutralized notion that cultural differences may result in students being unfit for a particular educational context (Castagno, 2014).

In what follows, we address the need for more work on education quality in the light of a specific North-South-South higher education collaboration titled the Culturally Responsive Education (CRE) network. With the aim of broadening our thinking around quality of education, we have sought to work with alternatives to dominant knowledges of the global North, if we ever hope to expand the notion of quality education in SDG4. We examine quality in the context of international higher education development cooperation by adopting a retrospective analytical approach in our collaborative learning process. We first describe the aims and content of the network, focusing in particular on one of its activities: an intensive course on qualitative research methods conducted collaboratively by researchers, MEd and PhD students from five universities from the global North and South. We also describe how the CRE approach was used to pay attention to the contextual relevance of education and discuss the limitations we now see in such an approach. Secondly, we analyse feedback from course participants to understand their approaches to cultural responsiveness and alternative knowledges. Third, through a retrospective self-study process, we discuss the opportunities and limits of our initial aims and perspectives, and how 
well the intensive course was able to encourage epistemological awareness, defined here as engagement with alternative ways of knowing (De Sousa Santos, 2016). In the context of this study, the academic collaboration across cultural, disciplinary and geographical contexts provided opportunities for such engagement, with the potential of problematizing one's own positionalities and epistemological perspectives. Our main question is whether North-South-South collaboration can become a context for working towards quality education through enhanced epistemological awareness and, if so, based on what conditions?

\section{The culturally responsive education approach as a pedagogical tool in North-South-South collaboration}

The CRE network enabled almost 100 students and staff members from two continents, four countries, five universities and six faculties and institutes (Faculty of Education, University of Cape Coast, Ghana; Faculty of Education, University of Dar es Salaam, Tanzania; Institute for Women's and Gender Studies and Department of Education Management and Policy Studies, University of Pretoria, South Africa; Faculty of Education, University of Jyväskylä, Finland; Institute of Behavioural Sciences and Department of Teacher Education, University of Helsinki, Finland) to take part in activities including student and teacher exchanges, one online course, one intensive course, network meetings and administrative visits between 2012 and 2016. This article focuses on a face-to-face one-week intensive course organized in November 2015 in Ghana. The participants were from Ghana $(n=45)$, South Africa $(n=5)$, Tanzania $(n=6)$, and Finland ( $n=15)$ (Janhonen-Abruquah et al., 2017). To further profile the group, participants came from various ethnic, racial and religious groups and with varying socio-economic status. Some participants from Finland, a third, included people born in African countries and who lived in African countries for a significant portion of their lives. Two of the authors participated in the intensive course with teaching and organizing responsibilities and one worked in development education tasks in Eastern Africa. The aim of the intensive course was to enhance participants' understanding of key concepts, terms and assumptions related to qualitative research and to develop the skills necessary for CRE by paying attention to aspects of cultural responsiveness and social justice, including their contextual implications.

Before the course, participants worked in cross-university groups, each of which was led by a tutor. Students chose two articles from a literature list covering qualitative research methods, classroom studies and theoretical readings of postcolonialism and social justice. Though we support most of the materials listed, we also recognize the North-centric nature of the list as a whole. Students discussed the texts online in cross-university groups. In addition, they used common guidelines either to collect qualitative observation data from a school in their respective country or to prepare a presentation on their ongoing qualitative research work.

Each of the five course days in Ghana had a specific focus:

- contextualizing theories, concepts and research ethics

- an introduction to qualitative data collection strategies

- a school visit

- analysing and interpreting qualitative data

- cultural responsiveness, social justice and equality in educational research.

In addition, participants visited a rainforest park and a slave castle and understood the beauty of the area and its shocking history. During the intensive course, the 
observation data collected in home universities were shared and analysed in mixed groups of students from all participating universities. The coordinating teachers from each participating university provided reading materials, guided the discussions of the participants' observation notes, and documented students' learning experiences. Students' presentations on their own research took place in a seminar setting, enabling peers and coordinating teachers to provide constructive feedback.

\section{Materials and methods}

This article uses participant feedback from a qualitative online questionnaire developed by the organizing team and administered to all participants of the intensive course. The online questionnaire was developed to provide a complementary feedback mechanism to the general programme level feedback collected by the funding organization (the Finnish Centre for International Mobility), focusing on participants' overall evaluation of the North-South-South programme. Recognizing the limitations of the available tools and being acutely aware of our evolving epistemologies and convictions, this article attempts to critically analyse the tools themselves and to identify opportunities for further qualitative work. Feedback was collected within a month after the intensive course. Overall feedback suggested that the course was, for most participants, a transformative success. With logistical, travel and accommodation arrangements made, participants believed they had meaningful learning experiences in a collaborative, cross-cultural group. However, it is worth acknowledging that funding organizations and course organizers typically collect feedback soon after the activity has concluded and that this feedback may thus be a good measure of personal experience but provide little information on longer-term impact. In this article, our interest extends beyond immediate participant feedback. The whole process of organizing the course is analysed as an effort to learn about qualitative research collaboratively across contexts and institutions, thereby building a basis for thinking with alternative knowledges.

The qualitative participant feedback collected by the course organizers came from 16 respondents from four countries and five universities. The respondents are BA and PhD students, as well as academic staff. The age range of respondents is from 22 to 50 . The questions that we focus on in our analyses include the participants' reasons for attending, what they found to be the more important learning experiences, how they assessed the course's working methods, and what they considered to be the definition and relevance of CRE.

We analysed the material using a qualitative content analysis (Schreier, 2014). This article is the result of two rounds of analysis conducted as a self-study (Zeichner, 2007) by the course organizers. The first round of analysis focused on identifying participants' most important learning experiences in relation to their original expectations and their perceptions of cultural responsiveness. Findings from the first analysis were presented at an international education development conference. The limited amount of feedback and relatively thin descriptions provided motivated further reading and critique. During the second round, we examined the respondents' feedback for indications of emerging thinking of alternative knowledges and looked at the feedback instruments and process of giving feedback in order to better understand the nature of their responses. We conducted all thematic interpretation and analyses collaboratively, mostly in an online environment and sometimes face to face. The collaborative process prompted engagement with new literature that led to more discussion and more reading in praxis-like fashion. The process shaped our thinking regarding the limits of cultural responsivity theory and the importance of paradigmatic discussions 
in higher education. We were able to discern inherent challenges that North-centred development education funding instruments bring for genuine inclusion of Southern knowledges and perspectives. It is a limitation that we must use Northern-dominated methodologies in order to convince researchers to understand Southern points of view. Our enlarged understanding equipped us to analyse the course feedback with a retrospective lens. The following section presents the key findings and is organized around the two analytical rounds.

\section{From participants' reflections towards thinking of alternative knowledges}

\section{Reasons for participation and most important learning experiences}

In the course evaluation, both student and academic staff participants were asked to state their main reasons for attending the intensive course. The reasons given were related to learning about qualitative methods and support for their own research (10 responses), opportunity for international collaboration and knowledge sharing (10) and learning about cultural responsiveness and the relationship between education and culture in general (10). It is to be noted that these responses were given just after the course, so as well as being a reflection on participants' reasons for applying to the course, they also describe the degree to which participants valued the collaborative process in general. On the evaluation form, participants were asked to describe the course's more important learning experiences. The responses were related to qualitative methodology and techniques (29), collaborative work modalities (20), and learning about culture and contexts (7).

Although no separate questionnaire was administered prior to the course, the participant evaluation questionnaire included questions related to expectations and reasons for attending the course. During the analysis, attention was given to the transformative nature of participants' perspectives. A comparison of participants' reasons for applying and their top learning experiences points to the central role of qualitative research during the course. The international, collaborative nature of the course was appreciated both in the expressed expectations and in the postcourse reflections, while culture and contexts were only explicitly mentioned in seven responses.

The participants' learning objectives related to qualitative research portrayed a variety of learning needs. For some participants the course provided an introduction to qualitative research in general. Learning outcomes related to qualitative methodology and methods for data collection and analysis were reported by all respondents. Practising qualitative techniques in groups was one of the more successful activities:

Share cultural experiences with my colleagues through narration of stories about a day in a school. (Participant 6)

The action research workshop: We were dealing with a case from an overcrowded school. It was interesting to see how our group had very different perspectives but we were able to put them together. (Participant 16)

Participants also considered the course an opportunity for collaborative professional development and sharing of knowledge and experiences across contexts: 'Exchange of expertise and support' (Participant 4); ' growing as researcher, collaborate with other researchers, networking and personal enrichment' (Participant 7). 
Learning more about culture(s), cultural responsiveness and multicultural societies was mentioned ten times as a reason for participation. Some responses reflected participants' more general interest in exploring cultures: 'To learn more from different cultures and what other students are doing in other countries' (Participant 8). Learning outcomes related to culture(s) and contexts included both theoretical and practical outcomes, while participants considered the intensive course to have helped in understanding of both oneself and of others:

Conceptualizing education and teaching in the light of culturally responsive manner in our own particular contexts. (Participant 5)

To understand how the issues of the academy in a home context resonate with issues in other contexts. (Participant 9)

Here, culture is used to refer to a national culture or context as if it were homogeneous, thus obscuring contextual or other differences, personal identifications and power. Difference and inferiority came up in one answer related to the context: 'How different schools Ghanaians have and poor facilities' (Participant 10). Differences (cultural, contextual, national and personal) were mentioned more than 30 times, while cultural similarities were mentioned only three times.

The respondents highly valued the collaboration and knowledge sharing between students and staff from each faculty from the five universities, as well as the varied activities and work modalities. The school visit in particular, which was linked to course assignments and group activities, was a key learning experience. However, participants also appreciated the presentations given by academic staff, particularly when there was adequate time for questions and discussion. Similar to the findings of Lehtomäki et al. (2016) on learning in a global seminar, a combination of diverse teaching and learning modalities proved conducive to collaborative learning across contexts. In a diverse group of participants, it is particularly important to include a variety of techniques that enable experiential learning, participation and engagement.

\section{Definitions and relevance of CRE according to participants}

What was notable when asking participants to identify the most important things learned was the connection they made between the qualitative research methods and cultural responsiveness, the core idea when planning the intensive course. Only one respondent mentioned the concept of cultural responsiveness when explaining why they had applied for the course: 'To improve my knowledge and understanding of culturally responsive education and qualitative research methods' (Participant 8). When giving their own definitions of CRE after the course, participants emphasized awareness and sensitivity to diversity and the importance of contextuality in education:

I think it means sensitive and conscious teaching, knowing the background of your students well and consider the background on your teaching. (Participant 11)

The way education, teachers and learners may incorporate cultures of different people in same setting, such as a classroom. (Participant 14)

It is important to think how to teach about values related to the nature or traditions. (Participant 16)

Participants also found the concept useful beyond the context of a classroom and outside of the interpretation of culture as exclusively national: 
The term has a much wider meaning for me after our workshop, incorporating work, organizational and learning cultures. As a person interested in the HR side of education, it is interesting how different educational organizations manage and value their staff. (Participant 7)

While cultural differences, support and respect were mentioned often, power issues were mentioned in only two answers:

Is the teaching, learning, resources, methods and interaction (pedagogy) which suits the context. In this case the CRE will cut the chains of prejudice, stereotypes, discrimination. (Participant 3)

I would say CRE is contextual, socially just, and sensitive to epistemological issues. (Participant 9)

Two participants thought that the intensive course itself reflected the concept of CRE:

Different students and academics from diverse backgrounds (educational and otherwise) coming together to learn from one another. (Participant 4)

I think our intensive course was all about culturally responsive education ... Participants were open to share their own experiences and were eager to learn from each other. We had shared goals but I am sure everyone learned and developed as a human somehow also. (Participant 16)

Discussing the relevance of CRE, the respondents provided examples of personal relevance (seven times) and general societal relevance (nine times). Two participants explicitly discussed both dimensions. When reflecting on CRE's personal relevance, the participants emphasized issues related to professional growth as a teacher or researcher:

It awakened my mind to have [a] positive attitude towards each group of people. Furthermore, as a teacher I learned the way students will be treated in the classroom or school regarding their cultural identities. (Participant 6)

As a part-time lecturer at [name of institution] I need to acknowledge, accommodate and respect a usually diverse group of lecturers as well as students. The workshop has made me more sensitive and aware in my approach and preparation. (Participant 7)

In line with Gay's approach respondents saw the value for teaching and learning in schools with respect to CRE. They reported that without CRE many children would be 'excluded from the learning process' (Participant 8) and 'it provides a clue about the kinds and nature of learners from different cultural backgrounds' (Participant 5). However, such a notion of culture can easily minimize or ignore contextual discrepancies and lead to essentialization and individualization of learners (Gay, 2013). An unfortunate consequence is that students from lower socio-economic groups or classes are considered less motivated:

My students are all from [the] same ethnic background, but their families have differences in their economic and social status. For me, knowing their home situations help[s] me to understand their motivation at school, for example. (Participant 11) 
At a more general level, participants found the cultural responsiveness approach a useful means of both recognizing diversity and talking about power issues, both in their own contexts and in the global world:

In my country the critical issue is gender imbalance in education ... where girls become the victim of cultural socialization and economic inequalities. (Participant 12)

The world is going to be even more global, and we have to think about how to deal with cultural issues in our small communities but also around the whole world. (Participant 16)

The range of participants' responses to questions about the definitions and relevance of CRE indicate its value for professional development, for understanding educational contexts from a cultural perspective, and for looking beyond one's own immediate contexts. However, one participant suggested that:

there are terms and theories that might better grasp the issue than just cultural responsiveness ... I think culturally responsive education is a bit of a loose term because the 'culture' can be interpreted in so many different ways. (Participant 9)

During the course, participants engaged in discussions on culture and cultural differences, and there were a number of different interpretations of these concepts. Some respondents emphasized culture in a more traditional sense, while the more critical ones talked about the problems that will emerge if we put more emphasis on cultural differences rather than inequalities between people, or if we misinterpret that 'norms' are the same thing as 'culture' and they explain how people are and how they behave.

During the collaboration we identified several problems with using CRE as a theoretical approach. The first, discussed above, was how CRE limits our abilities to discuss structural inequalities in diverse contexts. The second is the difficulty with translating a US-based theory to North-South-South collaboration in a meaningful way. The third is ensuring that, when focusing on contextual differences between countries, the differences within contexts are not obscured. If contextual differences are obscured, countries like Ghana, South Africa, Finland or Tanzania could look internally homogeneous (that is, like an essentialist interpretation of culture). The fourth concerns whether the theory of cultural responsiveness can be translated into different contexts. If so, can it be done well when meaningful discussions about race and inequalities are obscured? We believe not, especially when the notion of irreconcilable cultural differences, referring to clash of cultures, has become a central justification for discrimination in racist thinking (Lentin and Titley, 2011). These issues are considered further in the discussion section of the article.

\section{Emerging thinking of alternative knowledges}

A course focusing on qualitative research methods is also an opportunity to question epistemologies in African academic contexts, in which quantitative approaches dominate. The pre-assigned course readings encouraged participants to think about observation and interpretation of observation as an approach for developing personal engagement with research contexts. The readings also gave ideas for a critique of dominant forms of knowledge, as reflected in one of the responses: 
Another issue is how the valuable traditional experience and education [can] be uplifted to help bridge the gap between Western education and local knowledges. (Participant 12)

The interest in philosophical issues related to qualitative research was a major reason for one participant to apply to the course:

Enhanced capacity to understand and practise philosophical underpinnings of qualitative research and its data analysis. (Participant 14)

Using various work methods before and during the course enabled participants to take diverse perspectives. The school observations in home countries and in Ghana provided a context for rethinking assumptions:

Home school visits in Ghana were enriched because of the contextual experience and for comparison purposes. Group work whether in my home country or Ghana was a good part of learning for knowledge sharing and learning about the actual learning environment. The online course and exchange, whether online or intensive as we did in Ghana, cemented the idea of group experience and learning. (Participant 12)

When you learned something from each element, new information and experience were constructed upon previous knowledge bases. For example, the school observation in Ghana gave perspective both to local education and gave a point of comparison to the Finnish upper primary school that I observed. (Participant 13, translated from Finnish)

The tasks before and during the intensive course provided opportunities for engagement and learning at different levels. Some participants got by with existing structures of knowledge focusing on individual travel experiences, whereas others learned more deeply about epistemologies, qualitative research, social justice and the context through collaborative research training and international collaboration, and everything in between.

Beyond the intensive course analysed here, the CRE network of five universities provided opportunities for individuals to work on their qualitative research under supervisors from other universities. The course assignments and individual research can be seen as a means of diversifying knowledges. The collaborative research conducted within the CRE network in cross-cultural teams (Posti-Ahokas et al., forthcoming; Janhonen-Abruquah et al., 2017; Nketsia et al., 2017) has provided opportunities for collaborative, critical work on knowledge production, thus utilizing the unexploited potential for learning about each other's worlds through collaboration (Akkerman et al., 2006; Barrett et al., 2014).

In addition to assessing the intensive course itself, the feedback can be analysed as a potential context for questioning and critique. In general, we felt that the participants' feedback was brief and uncritical. This raised questions about the quality of the feedback tools used. An attempt was made to develop open-ended questions, allowing for a greater variety of voices and opinions. However, the resulting questionnaire was introduced more as a feedback tool than a research questionnaire: 'This questionnaire is part of the monitoring of the Network activities and it also contributes to ongoing research on intercultural learning and internationalization of higher education' (excerpt from the questionnaire introduction, sent two weeks after the course). The types of questions and the fact that the e-questionnaire did not clearly 
indicate that responses could be of any length may have resulted in respondents answering quickly and focusing on practical and programmatic issues.

One opportunity for uncritical feedback may lie in the funding structure of the intensive course. Participants' travel, insurance, accommodation and living expenses were all covered by the network. This substantial financial support might have made participants feel indebted to the network and reluctant to express deeper, more critical feedback. Some may also have considered the role that participant satisfaction might play in how the course was evaluated and whether the network might receive future funding. The suggestions provided by participants all related to extending the duration of the course or to the programme structure rather than to the course content or level of complexity. Therefore, rather than reflecting on the course critically, the feedback tended to assess the course based on its fitness for purpose and value for money.

As shown in this analysis, the qualitative questionnaire provided information on more course-specific feedback, including detailed information on the participants' expectations and learning experiences. However, it is evident that the available feedback tools did not encourage criticism of the course, the North-South-South network, or its funding mechanism as a whole. A future challenge will be looking for alternative methodological tools that allow course feedback to include deeper, more critical layers of thinking from participants. Finding a stronger connection between technical forms of evaluation and evaluative research would also be of benefit to the programme, in line with the recommendations given in the most recent evaluation of Finnish higher education development cooperation (Salmi et al., 2014). North-SouthSouth collaboration is often funded through development cooperation instruments, inherently placing questions of power and reciprocity in the centre. Allowing critique of current practices and funding mechanisms would enable deeper learning in the context of North-South-South collaboration and support epistemological awareness and critique as a stated goal of internationalized higher education.

\section{Discussion}

In this article, we have discussed how we aimed to emphasize epistemological awareness in a North-South-South collaboration, as well as some of the opportunities and limits of our own perspectives and how those perspectives translate into different contexts. The analysis of participant feedback indicates that the course provided opportunities for learning about participants' own contexts and others, based on a CRE approach. Pre-assigned tasks, the content of the course and activities (and related discussions) that took place during the course also provided tools for critiquing our thinking about CRE and qualitative research, and for working on epistemologies. At the same time, the network and the course relied on and contributed to understandings of culture and cultural differences. These were also echoed in the course feedback, in which CRE was mentioned mostly in the context of cultural differences and, in some cases, even in a context of cultural inferiority, thus echoing the previous critique of the CRT (Beauboeuf-Lafontant, 1999; Castagno, 2014). Some respondents, however, also considered power issues and how to tackle these in their school contexts.

A more profound scrutiny of epistemological stances could be useful to guide our understanding of cultural and contextual differences. Postcolonial, critical whiteness, critical pedagogy and social justice approaches introduced during some course activities and pre-assigned articles provided tools for critiquing epistemological stances. Accordingly, we would recommend a greater emphasis on such approaches, examining the convictions and histories of the theories we use, how these theories 
enable or prevent us from seeing and acting on certain issues, and what the outcomes might be for people in terms of power dynamics. Academic North-South-South collaboration has the potential to provide spaces for this kind of critical work, given that the diversity of perspectives available might broaden all participants' perspectives.

While the contextual comparisons throughout the course provided opportunities for interesting investigation, they also reinforced some prevailing ways of thinking, in which differences are approached from a cultural/national/country-based perspective. How the context is defined by matters, because focusing on context can clarify or obfuscate understanding. Cross-contextual comparisons have a risk of erasing differences within contexts and overemphasizing differences between contexts, and this can lead to an oversimplification of the issues. Moving from simplification towards recognition of diversities and commonalities requires not only expert guidance but also bolder experiments in cross-contextual learning and international collaboration (Lehtomäki et al., 2016, 2019). Such experiments could include learning about the process of accepting points of view from other cultural frames. This kind of collaboration can expand our 'epistemological, methodological and pedagogical horizons' (Barrett et al., 2014: 68).

Enhancing educational quality and epistemological awareness through international collaboration is an incremental process. Moving from educational tourism and cultural comparisons to collaborative learning and professional growth requires time and effort. Using diverse ways to collect feedback and conducting research to identify the impact of collaboration is necessary for developing activities that not only serve the needs of funding agents and higher education governance but also support epistemological awareness and learning across contexts.

If the aim of higher education, and development education in particular, is to move beyond adopting old approaches and tools towards the creation of new tools with global relevance (Andreotti et al., 2010), then paradigmatic explorations play a central role. Openness towards epistemological awareness may enable scholars to ask two important questions. The first is, can educational quality include the idea of transformative education that creates understanding about something that we cannot yet define by using our existing perspectives? The second is, how do we as educators prepare our students for what we do not yet know? Answering such questions could also provide genuine opportunities for creating qualitative, contextual understandings and tools for tackling the critical issues of quality, equity and cultural sustainability within the SDG4.

\section{Acknowledgements}

This work was supported by the Suninen and Troberg Foundation, HEED project (https://blogs.helsinki.fi/heedproject/); Academy of Finland under Grant 264654; and the Swedish School of Social Science at the University of Helsinki.

\section{Notes on the contributors}

Anna-Leena Riitaoja, PhD, Docent (diversity and teaching profession in education, University of Oulu), works as a postdoctoral researcher and research fellow in the Swedish School of Social Science at the University of Helsinki. Her research interests are intercultural education, social justice, epistemologies of higher education and professionalism and professional knowledge building in education and in social work. 
Hanna Posti-Ahokas, PhD, Docent (intercultural teacher education), is a senior researcher at the University of Jyväskylä, Finland. Her current research focuses on internationalization of higher education through North-South collaboration. She has lead and participated in various collaboration projects with universities from Tanzania, Ghana, South Africa and Eritrea.

Hille Janhonen-Abruquah, PhD, Docent (home economics science and education), is a university lecturer at the University of Helsinki, Faculty of Education. Her current research and teaching interests focus on consumer education, cultural sustainability, families in multicultural societies and culturally responsive teaching. During her long teaching career, she has led several cooperation projects with African and Nordic universities. She was the coordinator for the Culturally Responsive Education NorthSouth-South network. Currently she is the leader of the Home Economics Education for Diversities (HEED) research project, which develops means to better understand the gender and cultural differences in education.

\section{References}

Akkerman, S., Admiraal, W., Simons, R.J. and Niessen, T. (2006) 'Considering diversity: Multivoicedness in international academic collaboration'. Culture and Psychology, 12 (4), 461-85.

Andreotti, V. (2010) 'Postcolonial and post-critical "global citizenship education"'. In Elliott, G., Fourali, C. and Issler, S. (eds) Education and Social Change: Connecting local and global perspectives. London: Continuum, 238-50.

Andreotti, V., Fa'afo, A. and Giroux, M. (2010) 'Shifting conceptualisations of knowledge and learning in the implementation of the New Zealand curriculum: Conceptual models and a preliminary analysis of data'. Waikato Journal of Education, 15 (1), 29-47.

Andreotti, V., Stein, S., Ahenakew, C. and Hunt, D. (2015) 'Mapping interpretations of decolonization in the context of higher education'. Decolonization: Indigeneity, Education and Society, 4 (1), 21-40.

Baijnath, N. and James, G. (2015) 'Development priorities for African universities'. International Journal of Development Education and Global Learning, 7 (2), 61-74.

Barrett, A.M., Crossley, M. and Fon, T.P. (2014) 'North-South research partnerships in higher education: Perspectives from South and North'. In Streitwieser, B. (ed.) Internationalisation of Higher Education and Global Mobility. Oxford: Symposium Books, 59-71.

Beauboeuf-Lafontant, T. (1999) 'A movement against and beyond boundaries: Politically relevant teaching among African-American teachers'. Teachers College Record, 100 (4), 702-23.

Bhambra, G.K. (2014) Connected Sociologies. London: Bloomsbury Academic.

Biesta, G. (2009) 'Good education in an age of measurement: On the need to reconnect with the question of purpose in education'. Educational Assessment, Evaluation and Accountability, 21 (1), 33-46.

Blommaert, J. (2016) 'Research training and the production of ideas'. Ctrl+Alt+Dem blog, 13 January. Online. https://tinyurl.com/y3a4oxb5 (accessed 18 August 2019).

Bourn, D. (2014) The Theory and Practice of Global Learning (DERC Research Paper 11 for the Global Learning Programme). London: Development Education Research Centre.

Castagno, A.E. (2014) Educated in Whiteness: Good intentions and diversity in schools. Minneapolis: University of Minnesota Press.

De Sousa Santos, B. (2016) 'Epistemologies of the South and the future'. From the European South, 1, 17-29.

Foucault, M. (1980) Power/Knowledge: Selected interviews and other writings, 1972-1977. Ed. Gordon, C. Trans. Gordon, C., Marshall, L., Mepham, J. and Soper, K. Brighton: Harvester Press.

Gay, G. (2010) Culturally Responsive Teaching: Theory, research, and practice. New York: Teachers College Press.

Gay, G. (2013) 'Teaching to and through cultural diversity'. Curriculum Inquiry, 43 (1), 48-70.

Holmarsdottir, H.B., Farag, A.I. and Nomlomo, V. (2013) 'North-South-South collaboration: Old ideas in new boxes?'. Compare: A Journal of Comparative and International Education, 43 (2), 281-6. 
Jain, M. (2013) 'McEducation for All: Whose agenda does global education really serve?'. Critical Literacy: Theories and Practices, 7 (1) 84-90.

Janhonen-Abruquah, H., Lehtomäki, E. and Kahangwa, G.L. (2017) 'Culturally responsive education: From vision to practice'. In Lehtomäki, E., Janhonen-Abruquah, H. and Kahangwa, G.L. (eds) Culturally Responsive Education: Reflections from the global South and North. London: Routledge, 3-14.

Lehtomäki, E., Moate, J. and Posti-Ahokas, H. (2016) 'Global connectedness in higher education: Student voices on the value of cross-cultural learning dialogue'. Studies in Higher Education, 41 (11), 2011-27.

Lehtomäki, E., Moate, J. and Posti-Ahokas, H. (2019) 'Exploring global responsibility in higher education students' cross-cultural dialogues'. European Educational Research Journal, 18 (2), 218-33.

Lentin, A. and Titley, G. (2011) The Crises of Multiculturalism: Racism in a neoliberal age. London: Zed Books.

Nketsia, W., Juma, S.K., Malle, A.Y., Pirttimaa, R. and Lehtomäki, E. (2017) 'Dialogues on culture(s) of inclusion between African and Finnish educators'. In Lehtomäki, E., Janhonen-Abruquah, H. and Kahangwa, G.L. (eds) Culturally Responsive Education: Reflections from the global South and North. London: Routledge, 163-73.

Odora Hoppers, C.A. (2015) 'Cognitive justice and integration without duress: The future of development education - perspectives from the South'. International Journal of Development Education and Global Learning, 7 (2), 89-106.

Posti-Ahokas, H., Janhonen-Abruquah, H. and Adu-Yeboah, C. (forthcoming) 'From cultural visits to intercultural learning: Experiences of North-South-South collaboration'. In Dervin, F., Moloney, R. and Simpson, A. (eds) Intercultural Competences in the Work of Teachers. Routledge.

Richards, H. (2015) 'Modernity's "other" and the transformation of the university'. International Journal of Development Education and Global Learning, 7 (2), 6-25.

Salmi, J., Mukherjee, H., Uusihakala, J. and Kärkkäinen, K. (2014) Evaluation: Finland's support to higher education institutions: North-South-South and HEI ICI Programmes. Helsinki: Ministry for Foreign Affairs of Finland.

Sayed, Y. and Ahmed, R. (2015) 'Education quality, and teaching and learning in the post-2015 education agenda'. International Journal of Educational Development, 40, 330-8.

Schreier, M. (2014) 'Qualitative content analysis'. In Flick, U. (ed.) The SAGE Handbook of Qualitative Data Analysis. London: SAGE Publications, 170-83.

Shokane, A.L. and Masoga, M.A. (2018) 'African indigenous knowledge and social work practice: Towards an Afro-sensed perspective'. Southern African Journal of Social Work and Social Development, 30 (1), 1-18.

Skinner, A., Blum, N. and Bourn, D. (2013) 'Development education and education in international development policy: Raising quality through critical pedagogy and global skills'. International Development Policy - Revue internationale de politique de développement, 4.3. Online. https:// journals.openedition.org/poldev/1654 (accessed 18 August 2019).

Stein, S., Andreotti, V. and Suša, R. (2019a) "'Beyond 2015", within the modern/colonial global imaginary? Global development and higher education'. Critical Studies in Education, 60 (3), 281-301.

Stein, S., Andreotti, V. and Suša, R. (2019b) 'Pluralizing frameworks for global ethics in the internationalization of higher education in Canada'. Canadian Journal of Higher Education, 49 (1), 22-46.

Zeichner, K. (2007) 'Accumulating knowledge across self-studies in teacher education'. Journal of Teacher Education, 58 (1), 36-46. 